\title{
A banalidade do mal na narrativa de Lília Momplé
}

The banality of evil on Lília Momplé's narrative

\author{
$\underline{\underline{\text { Maria Teresa Salgado }}}$
}

1 Professora de Literaturas Africanas de Língua Portuguesa, da Faculdade de Letras da Universidade Federal do Rio de Janeiro. É líder do grupo de pesquisa Escritas do Corpo Feminino, credenciado pelo CNPq. 
RESUMO: Leitura dos contos da obra Ninguém matou Subura, da escritora moçambicana Lília Momplé, a partir do conceito de banalidade do mal, de Hannah Arendt. Procuramos mostrar de que forma o conceito pode ser empregado para entendermos a natureza do mal em algumas situações do colonialismo. Hanna Arendt nos ofereceu um caminho para refletir sobre a capacidade/incapacidade do homem de distinguir o mal do bem e desenvolveu reflexões que nos permitem compreender aspectos inusitados da relação entre os sistemas totalitários e o mal. Tentaremos apontar de que forma os contos de Lília Momplé, na obra Ninguém matou Subura, nos oferecem uma via de leitura próxima das ideias desenvolvidas por Arendt sobre "a banalidade do mal".

PALAVRAS-CHAVE: Banalidade do Mal; Colonialismo; Lília Momplé; Hannah Arendt; Ninguém matou Subura.

ABSTRACT: Reading of the short stories Ninguém matou Subura, by the Mozambican writer Lília Momplé, from Hannah Arendt's concept of banality of evil. We try to show how the concept can be used to understand the nature of evil in some situations of colonialism. Hanna Arendt has offered us a way to reflect on man's ability / inability to distinguish evil from good and has developed reflections that allow us to understand unusual aspects of the relationship between totalitarian systems and evil.We will try to point out how the tales of Lília Momplé in Ninguém matou Suhura give us a way of reading close to the ideas developed by Arendt on "the banality of evil."

KEYWORDS: Banality of evil; Colonialism; Lília Momplé; Hannah Arendt; Ninguém matou Subura. 
A barbárie não é um atributo dos bárbaros. Pode perfeitamente irromper entre povos muito civilizados.

Saul Kisrchbaun

Escolhi essa epígrafe porque ela sintetiza diversos pontos que aqui desejamos discutir sobre o conceito de banalidade do mal na obra da escritora moçambicana Lília Momplé. Nascida na Ilha de Moçambique, em 1935, a escritora publicou apenas 3 livros, mas recebeu diversos prêmios e obteve sucesso de público e de crítica com sua obra. Contudo, não é muito conhecida do público brasileiro. Mesmo entre os pesquisadores da área de africanas, a autora não é muito estudada. Interessa-nos, aqui, pensar a obra de estreia de Momplé, Ninguém matou Subura, livro de contos publicado em 1988. Discutiremos, especialmente, o conto "Epônimo", já que ele se apresenta como um dos mais emblemáticos das ideias do mal em questão.

O pesquisador Saul Kirschbaun (2018) nos aponta algumas questões importantes para a nossa discussão: recorda que o termo banalidade do mal foi extremamente incompreendido e distorcido após a publicação do livro de Arendt - Eichmann em ferusalém (1999). Muitos chegaram a declarar que não o leriam jamais. E até mesmo o filósofo Martin Buber rompeu a amizade com Arendt. Kirschbaum mostra que ainda hoje a expressão é empregada muitas vezes de forma equivocada e enfatiza que o mundo vive, cada vez mais, diversos conflitos, nos quais as ideias da pesquisadora sobre a banalidade do mal se aplicam. Considero importante, portanto, antes da discussão da obra de Momplé, fazer uma breve apresentação sobre a importância do conceito de Arendt para entendermos melhor a sua pertinência em relação ao texto literário enfocado.

Até o surgimento das ideias de Arendt, o mal costumava ser encarado, frequentemente, do ponto de vista religioso, como algo demoníaco, capaz de corromper os homens e explorar suas fraquezas morais. Mas a partir do julgamento de Adolf Eichmann, a pensadora alemã nos propôs uma reflexão sobre o tipo de maldade que se estabeleceu durante o regime nazista. Arendt participou do julgamento do carrasco e pôde observar, durante o tempo em que acompanhou seus depoimentos, que Eichmann era sobretudo um burocrata, um sujeito 
medíocre que não pensava sobre as consequências de seus atos. Ao declarar que as monstruosidades do nazismo haviam sido cometidas por homens comuns, Arendt não pretendia, de modo algum, isentá-los das suas responsabilidades. A filósofa simplesmente tentava entender o que acontecia na sociedade no sentido de abrir as fronteiras entre o bem e o mal.

O conceito de Arendt (1999) nos permite, em primeiro lugar, fazer uma aproximação entre as circunstâncias do Nazismo e as do Colonialismo. É a própria pensadora que estabelece essa ponte, quando discute as origens do totalitarismo, na obra do mesmo nome. Nesse texto, a filósofa já traz considerações sobre quais seriam as condições propícias ao surgimento do mal como algo banal, isto é, normalizado, na sociedade e no comportamento do homem. As crises políticas na Europa que levaram à expansão colonial produziram sociedades desagregadas (em maior ou menor escala). $\mathrm{Na}$ Alemanha, do advento do nazismo, vimos o contexto ideal de uma sociedade povoada de indivíduos que ansiavam por algo que os redimisse, prontos a "perder o eu" em favor de uma causa. Tudo que se fez, a partir do nazismo, foi pensado a favor da comunidade ariana.

Consideramos o contexto colonial português como extremamente favorável para que a violência se institucionalizasse. Encontramos em Portugal, sem dúvida, um quadro distinto do da Alemanha. Contudo, encontramos também um esfacelamento do tecido social e um projeto de redenção comunitária. "A ideia de que pertence à essência orgânica da nação portuguesa a missão histórica de colonizar territórios ultramarinos e civilizar os indígenas neles compreendidos é, desde logo, inscrita no Acto Colonial de 1930 e na Constituição de 1933" (CASTELO, 2007, p.132).

Guardando as devidas proporções, no contexto totalitário colonial, existem, portanto, aspectos que se assemelham ao contexto totalitário da Alemanha nazista. Tanto num como noutro, estamos diante de comunidades nas quais o projeto de redenção comunitária oferecido pelo líder vai gerar massas de indivíduos cada vez menos capazes de pensar por si mesmos. Desse modo, “A mística imperial, que nesta altura se procurava incutir nos portugueses, tem como objetivo estimular uma vocação inata”. (CASTELO, 2007, p. 132) Assim se pronunciava Salazar em seus discursos: "Ser escasso em território, reduzido em população ou em força (...) não limita de per si a capacidade civilizadora: um povo pode criar em seu seio princípios norteadores de acção universal, irradiar fachos de luz que iluminem o mundo" (CASTELO,2007, 
p. 132). Tal missão era, naturalmente, apresentada como um "chamamento das raças inferiores à nossa civilização cristã (CASTELO, 2007, p. 133).

Ademais, Arendt, em seu estudo do totalitarismo, vai nos mostrar, também, que é justamente longe da nação, de um modo geral, que o sujeito se sente capaz de identificar-se mais com ela: os membros das associações colonialistas e ligas imperialistas sentiam-se "bem distantes das lutas partidárias" e, quanto mais se afastavam da pátria, mais acreditavam "representar apenas o propósito nacional" (ARENDT, 1999, p. 184). Daí se depreende também toda uma mentalidade propícia a essa abertura das fronteiras entre o bem e o mal, que é o olhar burocratizado para o outro, isto é, incapaz de enxergá-lo como ser humano.

O discurso oficial do Estado Novo português tudo fez para glorificar esse passado nobre de seu povo, ligando-o ao presente da colonização. Convocava-se a dignidade própria de uma nação a reencontrar "nas profundas raízes da sua vocação, todas as forças para reconstruir o seu império intemporal”. (CASTELO, 2007, p. 133).

Encontramos, portanto, no colonialismo europeu, alguns dos elementos fundadores observados por Arendt no surgimento da ideologia nazista. Contudo, mais do que uma simples aproximação entre os aspectos do Nazismo e do Colonialismo europeu e português, desejo, aqui, apontar e discutir aspectos que nos permitam pensar mais claramente o conceito de $b a$ nalidade no mal no contexto colonial moçambicano.

Em todos os cinco contos da obra Ninguém matou Subura, encontramos um comportamento de brutalidade e desumanização extrema em relação ao colonizado, por parte do sistema administrativo. Presenciamos uma completa indiferença em relação ao ser humano atingido pela violência, em muitas instâncias e situações, contrariando a difundida ideologia lusotropicalista, que sugeria uma especial capacidade do português de se relacionar com outros povos.

A indiferença em relação ao colonizado se expressa, de modo assustador, em todos os contos do livro de Momplé. Por outro lado, o desejo de provocar no leitor uma reflexão sobre a história e os fatos acontecidos se expressa já nas datas e locais em que os episódios narrados se desenrolam. Esta é, aliás, uma característica das obras da autora, que aparece no romance Neighbours, publicado em 1999. Não apenas todos os contos nos oferecem, já na página de abertura, a marca do tempo e do espaço em que se situam os brutais acontecimentos narrados, mas também as epígrafes das obras de Momplé destacam a importância dessa história e 
dessa memória em relação ao passado, conforme lemos na abertura do livro Ninguèm matou Subura: "A felicidade jamais se alcançará definitivamente; é necessário conquistá-la dia a dia, com uma inabalável esperança no futuro, mas também com os ensinamentos do sofrimento passado."

O primeiro conto, “Aconteceu em Saua-Saua”, ocorre em 1935 e nos conta a história de Mussa Racua, um colonizado que nos é apresentado em meio a seu desespero na busca de um saco de arroz, que deve apresentar ao fim da colheita para administração colonial. Apenas um saco evitaria que ele fosse enviado à força para o contrato. Acompanhamos o drama de Mussa Racua e descobrimos que ele já havia passado pela experiência de ser enviado às desumanas plantações de contratados. Eis a razão pela qual ele termina optando por se matar a voltar à plantação e perder o pouco de humanidade que lhe resta. $\mathrm{O}$ conto termina com a seguinte frase proferida pelo administrador: "Estes cães, assim que lhes cheira a trabalho, arranjam sempre chatices. Ou fogem ou suicidam-se.” (MOMPLÉ 2004, p. 21).

O segundo conto, "Caniço", nos leva para 1945. Conhecemos Naftal e os percalços de sua família na luta para sobreviver, com o salário miserável, em casa de patrões sem nenhuma consideração ou respeito. Quando um relógio da patroa desaparece, Naftal é levado para a esquadra, acusado de roubo pelo patrão e espancado brutalmente. Mesmo quando o relógio aparece, nenhum dos dois se preocupa em avisar a polícia do engano. O patrão apenas comenta: “A queixa já lá está, não podemos voltar atrás. Deixa-os lá apanhar. É pelas vezes que roubam e não são descobertos." (MOMPLÉ, 2004, p. 35).

A cada narrativa do livro, a violência vai nos mostrando sua face naturalizada e insidiosa, atestando o olhar burocratizado sobre o outro enfocado por Arendt: no conto "O baile de Celina”, estamos em 1950. As atitudes violentas do sistema colonialista, embora se deem mais em nível psicológico, não deixam de ser estarrecedoras. Acompanhamos, aqui, a personagem Violante, cheia de satisfação a preparar o vestido que a filha Celina vai usar no baile de formatura. Violante passou a vida a estimulá-la: "Estuda, filha! Só a instrução pode apagar a nossa cor. Quanto mais estudares mais depressa serás gente” (MOMPLÉ, 2004, p.51 - grifos meus). Na véspera da formatura, porém, ao lado de um colega também mulato, Celina é chamada na escola e proibida de comparecer à festa: "Quero avisar-vos que não podem ir ao baile das finalistas - prossegue calmamente o reitor, pousando nos jovens seu olhar ausente de míope." (MOMPLÉ, 2004, p. 54). 
Mas a insensibilidade diante da dor e do sofrimento alheio chegam ao auge no conto "Ninguém matou Suhura", penúltima narrativa do livro, desenrolada em 1970, plena guerra colonial. Parece ser nesse momento que percebermos melhor o processo de desumanização ao qual se refere Arendt. O texto se divide em três partes, numa espécie de crônica-reportagem, que mostra o cotidiano no seio da sociedade colonial, construindo assim uma ante-cena do que assistiremos com o desfecho brutal do conto. Desse modo, somos introduzidos paulatinamente no cenário colonial e induzidos a refletir sobre os horrores presenciados. Na primeira parte, "O Dia do Senhor administrador", acompanhamos o dia a dia de um administrador colonial em Moçambique. A personagem do administrador não possui nome, corroborando o seu papel de mera engrenagem do sistema colonial. Sua personalidade, contudo, é analisada, desde as primeiras páginas do conto: "tem plena consciência da auréola que o envolve, devido à elevada posição que ocupa na Ilha, onde é simultaneamente Administrador de Distrito e Presidente da Câmara." (MOMPLÉ, 2004, p. 59). Seu passado de pobreza e falta de perspectivas corrobora o perfil do indivíduo disposto a tudo para alcançar um espaço redentor, como vemos na descrição feita no conto, a propósito do que o uniu a sua esposa:

\footnotetext{
Juntos vieram de Portugal e subiram sem desânimo as escadas da fortuna. Quando ele era ainda um simples aspirante do quadro administrativo, a mulher acompanhara-o por esse mato afora. Juntos humilhavam os negros e incutiam-lhes o desprezo por si próprios. Juntos exploravam os camponeses pobres e bajulavam os donos das plantações. (MOMPLÉ, 2004, p. 60)
}

Presenciamos a certeza tranquila de que os humilhados não merecem nada. Pelo contrário, a presença colonialista é transformada em um sacrifício altruísta da parte dos portugueses, que se dispuseram a trabalhar em prol da civilização de povos inferiores. Diversos discursos e decretos do período salazarista se encarregam de propagar a ideia do altruísmo e abnegação da missão colonial portuguesa. Note-se o incômodo do administrador quando se dá conta de que, a partir de um novo contexto, terá que cumprimentar os negros: "Corja de ingratos. Depois de tudo que fizemos por eles.” (MOMPLÉ, 2004, p. 62).

Assistimos, assim, à convicção da superioridade do colonizador e a total indiferença 
pelo colonizado dentro do circuito de violência banal e cotidiana do colonialismo. Ao final do conto, o administrador estrangula a jovem Suhura, simplesmente porque essa resistira ao seu apetite sexual, recusando-se à violência naturalizada:

Para além de um irritado espanto, o senhor administrador sente apenas uma estranha curiosidade em conhecer a causa dessa morte: teria violentado a rapariga de tal modo que provocasse uma hemorragia fatal? Ou, no meio da sua estúpida, teria ela própria batido com a nuca na cabeceira da cama? Ou morrera de puro susto? Interrogando-se assim intimamente, acaba de se vestir e sai do quarto, sem se voltar uma só vez.

Surpreendeu D. Júlia Sá no corredor. Esta estivera à escuta, como é seu hábito, e não pudera desaparecer a tempo.

- O estupor da negra morreu! - informa o senhor administrador, à queima roupa.

D. Júlia Sá hesita entre o desmaio e os altos gritos. Pelo que escutara, sabia que algo de insólito tinha acontecido, pois a luta surda que adivinhava através da porta, não era certamente um jogo de amor. Mas que tenha acabado em morte parece-lhe inacreditável. Contudo, o senhor administrador apressa-se a tranquilizá-la.

- Esteja descansada, nada vai lhe acontecer. Vou já mandar o Abdulrazaque e ele tratará de tudo, vai ver! Você escusa mesmo de entrar no quarto. - diz ele, dirigindo-se precipitadamente para a saída. (MOMPLÉ, 2004, p. 86)

Suhura é apenas mais um número na cadeia de violências perpetradas pelo colonialismo. Cada uma das personagens da narrativa de Momplé termina por revelar a forma como seres humanos se transformaram em meras engrenagens, a bem do funcionamento da máquina colonial. É muito natural, portanto, que o administrador, em momento algum consiga sentir remorsos pelo assassinato que comete. Tampouco qualquer um dos que colaboraram para que Suhura fosse retirada de sua casa e conduzida ao quarto onde seria violentada sentiram qualquer perturbação ao saberem de sua morte. $\mathrm{O}$ grito e o tremor da dona da casa onde Suhura foi morta parecem expressar antes o receio pelo que poderia lhe acontecer e não um lamento pelo assassinato da menina. Ela é logo acalmada pelo administrador: "Esteja 
descansada, nada vai lhe acontecer. Vou já mandar o Abdulrazaque e ele tratará de tudo, vai ver! Você escusa mesmo de entrar no quarto.” (MOMPLÉ, 2004, p. 87).

Hanna Arendt nos mostrou que, mais do que legitimar a irracionalidade e a barbárie, as circunstâncias do Nazismo criaram condições nas quais os homens parecem propensos a abrirem mão de sua condição de indivíduos, afastando-se da realidade e deixando de pensar. Os contos de Lília Momplé, portanto, nos levam a uma conclusão semelhante no que se refere ao colonialismo. 


\section{Referências Bibliográficas}

ARENDT, Hannah. Eichmann em ferusalém: um relato sobre a banalidade do mal. São Paulo: Companhia das Letras, 1999.

ARENDT, Hannah. Homens em tempos sombrios. São Paulo: Companhia das Letras, 2008.

CASTELO, Cláudia. O modo português de estar no mundo: o luso-tropicalismo e a ideologia colonial portuguesa (1933-1961). Lisboa: Edições Afrontamento, 2007.

KIRSCHBAUM, Saul. Hannah Arendt e a banalidade do mal-entrevista com Saul Kirschbaum. Disponível em: <http://ocontornodasombra.blogspot.com/2014/03/hannah-arendt-e-banalidade-do-mal.html>. Acesso em: 30 ago. 2018.

MOMPLÉ, Lília. Neighbours. 2a ed. Maputo: Associação dos Escritores Moçambicanos, 1999.

MOMPLÉ, Lília.. Ninguém matou Subura. 2a ed. Maputo: Edição Independente, 2004. 